\title{
Manejo de Plantas Daninhas no Plantio Direto da Soja (Glycine max) SOBRE O MILHETO (Pennisetum maximum) ${ }^{1}$
}

\author{
Weed Management Under Soybean (Glycine max) No-Tillage Cultivated over Millet \\ (Pennisetum maximum)
}

FREITAS, S.P. ${ }^{2}$, RODRIGUES, J.C. ${ }^{3}$ e SILVA, C.M.M. ${ }^{4}$

\begin{abstract}
RESUMO - Com o objetivo de avaliar diferentes manejos de plantas daninhas no plantio direto da soja, cultivada sobre palha de milheto (manejada com rolo-faca ou glyphosate), foram realizados dois experimentos com dois cultivares de soja (Conquista e Celeste) e aplicação em pós-emergência

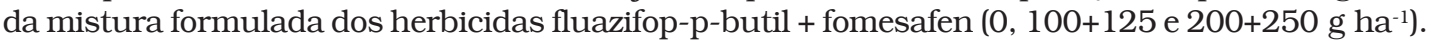
Por meio da análise de variância conjunta dos experimentos, verificou-se predominância de diferentes espécies de plantas daninhas em função do manejo dado ao milheto, sendo a maior infestação destas verificada sob o manejo com rolo-faca associado à ausência de controle na cultura da soja. Há a possibilidade da redução da dose de fluazifop-p-butil + fomesafen para o controle de plantas daninhas na soja, desde que precedida da aplicação de glyphosate para formação da palha de milheto. Sob esta condição, verificou-se maior controle das espécies daninhas, em relação ao manejo mecânico (rolo-faca), resultando em maior produtividade da cultura, devido à maior quantidade de vagens por planta e de grãos por vagem.
\end{abstract}

Palavras-chave: cobertura morta, fluazifop-p-butil, fomesafen, glyphosate, rolo-faca.

\begin{abstract}
The aim of this study was to evaluate different types of management methods under soybean no-tillage cultivated over pearl millet straw (managed with cutting-roller or glyphosate). Two experiments were carried out with two soybean cultivars (Conquista and Celeste) and post-emergence application of the formulated mixture of the herbicides fluazifop-p-butyl + fomesafen $\left(0,100+125\right.$ and $\left.200+250 \mathrm{~g} \mathrm{ha}^{-1}\right)$. Conjoined variance analysis of the experiments showed predominance of different weed species over pearl millet management with the greatest infestation of the former being verified under cutting-roller management associated to control absence in the soybean crop. The fluazifop-p-butyl + fomesafen dose may be reduced for weed control in soybean provided it is preceded by glyphosate application to form pearl millet straw. Under this condition, greater weed control was verified in relation to mechanic management (cutting-roller), resulting in greater crop yield, due to the greater amount of pod per plant and grain per pod.
\end{abstract}

Keywords: cutting-roller, fluazifop-p-butyl, fomesafen, glyphosate, mulching.

\section{INTRODUÇÃO}

A soja constitui uma das culturas de maior relevância para a economia brasileira e, possivelmente, a que apresenta crescimento mais expressivo no cultivo e no segmento agroindustrial nacional (Chiappa, 2005). Em razão das condições climáticas e de cultivo, o Brasil se destaca como segundo produtor mundial dessa cultura; todavia, o clima tropical também é bastante favorável à ocorrência de plantas daninhas, as quais interferem no crescimento, no desenvolvimento e na produtividade da soja (Barros et al., 2000). Além da

Recebido para publicação em 10.11.2005 e na forma revisada em 4.8.2006.

2 Professor da Universidade Estadual do Norte Fluminense - CCTA-LFIT/UENF, 28013-602 Campos dos Goytacazes-RJ; ${ }^{3}$ Enga.-Agrônoma, D.S. em Produção Vegetal. ${ }^{4}$ Doutorando, UENF-CCTA/LFIT, Bolsista do CNPq. 
competição pelos recursos do meio, a presença de plantas daninhas pode dificultar a colheita e aumentar o grau de impurezas em sementes ou grãos colhidos. As perdas da produção de grãos de soja em uma lavoura, devido à interferência das plantas daninhas, podem ser superiores a $80 \%$, dependendo da densidade e das espécies envolvidas (Chemale \& Fleck, 1982; Fleck \& Candemil, 1995).

Uma das tecnologias utilizadas no cultivo da soja é o sistema de plantio direto com formação de cobertura morta, cuja decomposição pode promover alterações a médio e longo prazos na população das principais plantas daninhas presentes na área (Vidal \& Theisen, 1999; Erasmo et al., 2004). A cobertura morta pode promover liberação de compostos alelopáticos (Nimbal et al., 1996), causar alterações físicas no solo (as quais podem afetar a germinação das sementes de espécies daninhas (Teasdale \& Mohler, 1993) e reduzir a disponibilidade da radiação solar (Facelli \& Pickett, 1991), o que pode refletir em redução da infestação de plantas daninhas. O sucesso no controle das espécies daninhas com a utilização de palha depende da época de manejo, da qualidade e quantidade desta, o que, no caso do milheto, tem variado de 5,0 (Bianchi, 1999; Lima, 2002) a $14 \mathrm{t} \mathrm{ha}^{-1}$ de palha (Oliveira et al., 2002).

O plantio direto é atualmente uma realidade, sendo comprovadamente causador de menor impacto negativo ao ambiente, comparado ao sistema convencional de plantio. Dessa forma, informações referentes ao melhor manejo de plantas daninhas nesse sistema, bem como estudos visando a diminuição de doses de herbicidas, são fundamentais para a boa execução do sistema. As espécies que não são controladas pela deposição dos resíduos vegetais da cultura anterior o são pela utilização de herbicidas, uma vez que o uso de cultivadores e capinas mecânicas é incompatível com a tecnologia utilizada no plantio direto. Correia et al. (2005) verificaram a possibilidade de redução de doses de imazamox quando associado aos resíduos de sorgo (Sorghum bicolor) no controle de plantas daninhas na cultura da soja.

Este trabalho foi realizado com o objetivo de verificar o controle de plantas daninhas na cultura da soja, em função de diferentes manejos da cobertura de milheto, associados à aplicação de doses de fluazifop-p-butil + fomesafen.

\section{MATERIAL E MÉTODOS}

Dois experimentos foram realizados na Estação Experimental do Centro de Ciências e Tecnologias Agrárias da UENF, no município de Campos dos Goytacazes-RJ, durante a estação de crescimento 2001/02. O solo da área experimental é classificado como Latossolo Amarelo (Embrapa, 1999), cuja análise é apresentada na Tabela 1.

O milheto (Pennisetum maximum) foi semeado a $2-3 \mathrm{~cm}$ de profundidade, após o preparo convencional do solo e a incorporação de calcário (400 kg ha-1), em outubro de 2001 , com densidade de 110 sementes $\mathrm{m}^{-1}$ e espaçamento de 0,30 m entre fileiras. Trinta dias após a semeadura (DAS), determinaram-se as espécies daninhas presentes na área.

Aos 90 DAS do milheto, foram instalados dois experimentos: no primeiro, a palha de $P$. maximum foi formada mediante a utilização de um rolo-faca e, no segundo, com a aplicação do herbicida dessecante glyphosate, na dose de 2,16 kg ha-1 e.a. (Rodrigues \& Almeida, 2005), utilizando-se um pulverizador tratorizado de barra com bicos do tipo leque XR 110.04, à pressão de $50 \mathrm{lb} \mathrm{pol}^{-2}$, calibrado para

Tabela 1 - Resultados da análise físico-química do solo da área experimental

\begin{tabular}{|c|c|c|c|c|c|c|c|c|c|c|c|c|}
\hline \multicolumn{13}{|c|}{ Análise físico-química } \\
\hline \multirow{2}{*}{$\begin{array}{l}\text { Profundidade } \\
\quad(\mathrm{cm})\end{array}$} & $\mathrm{MO}$ & Argila & $\mathrm{pH}$ & $\mathrm{P}$ & $\mathrm{K}^{+}$ & $\mathrm{Al}^{3+}$ & $\mathrm{Ca}^{2+}$ & $\mathrm{Mg}^{2+}$ & $\mathrm{H}+\mathrm{Al}$ & $\mathrm{CTC}_{\text {total }}$ & $\mathrm{V}$ & $\mathrm{m}$ \\
\hline & \multicolumn{2}{|c|}{$\left(\right.$ dag $\left.\mathrm{kg}^{-1}\right)$} & $\left(\mathrm{H}_{2} \mathrm{O}\right)$ & \multicolumn{2}{|c|}{$\left(\mathrm{mg} \mathrm{dm}^{-3}\right)$} & \multicolumn{5}{|c|}{$\left(\mathrm{cmol}_{\mathrm{c}} \mathrm{dm}^{-3}\right)$} & \multicolumn{2}{|c|}{$(\%)$} \\
\hline $0-20$ & 2,03 & 38 & 5,0 & 16 & 43 & 0,2 & 2,0 & 0,7 & 3,7 & 6,6 & 44 & 9 \\
\hline $20-40$ & 1,49 & 44 & 4,8 & 4 & 17 & 0,5 & 1,5 & 0,6 & 3,4 & 5,5 & 39 & 19 \\
\hline
\end{tabular}


aplicação de $500 \mathrm{~L} \mathrm{ha}^{-1}$ de calda. Portanto, a formação da palha de milheto mediante aplicação do herbicida ou utilização do rolo-faca consistiu-se em efeitos ambientais distintos.

Para determinação da massa seca da parte aérea (MSPA) do milheto, utilizou-se um quadrado de 0,5 $\mathrm{m}$ de lado, lançado aleatoriamente nas unidades experimentais. O material coletado foi seco em estufa com circulação forçada de ar, à temperatura de $60^{\circ} \mathrm{C}$, durante 48 horas. Após a determinação de massa seca, o material vegetal foi reposto ao local de coleta das amostras.

O delineamento experimental utilizado em ambos os experimentos foi em blocos casualizados, com quatro repetições e sob um arranjo fatorial $2 \times 3$, sendo dois cultivares de soja (Conquista - MG/BR-46 e BRS Celeste) e a aplicação em pós-emergência da mistura formulada dos herbicidas fluazifop-p-butil + fomesafen $\left(0,100+125\right.$ e $\left.200+250 \mathrm{~g} \mathrm{ha}^{-1}\right)$. As unidades experimentais foram representadas por quatro linhas espaçadas de $0,50 \mathrm{~m}$, com $6,0 \mathrm{~m}$ de comprimento, totalizando $12 \mathrm{~m}^{2}$, sendo a área útil de $5,0 \mathrm{~m}^{2}$.

Os cultivares de soja foram semeados no sistema de plantio direto, aos 30 dias após a formação da palha, no espaçamento de $0,5 \mathrm{~m}$ entre linhas, com estande final de 396.000 plantas ha-1. A adubação de plantio foi feita com $500 \mathrm{~kg} \mathrm{ha}^{-1}$ de $\mathrm{Ca}\left(\mathrm{H}_{2} \mathrm{PO}_{4}\right)_{2} \cdot \mathrm{H}_{2} \mathrm{O}$ e $200 \mathrm{~kg} \mathrm{ha}^{-1}$ de $\mathrm{KCl}$, de acordo com a análise química do solo. No dia anterior à semeadura, estirpes específicas de Bradyrhizobium japonicum (SEMIA 587 e SEMIA 5019) foram inoculadas às sementes de soja. Aos 45 dias após a emergência (DAE), foi efetuada a adubação potássica em cobertura com $100 \mathrm{~kg} \mathrm{ha}^{-1}$ de $\mathrm{KCl}$. Os demais tratos culturais foram realizados de acordo com as recomendações para a cultura, com exceção do manejo de plantas daninhas. A colheita foi realizada manualmente, cortando-se as plantas rente ao solo, submetendo-as posteriormente à secagem e debulha manual.

Foi determinado o número de vagens por planta e de grãos por vagem, em 10 plantas amostradas na área útil da unidade experimental, assim como a produtividade de grãos dos cultivares, com teor de umidade corrigido para 13\%. O peso de 100 grãos foi obtido pela contagem e pesagem de uma amostra retirada do total de grãos colhidos dentro da área experimental, bem como pela quantidade de grãos chochos (grãos que se apresentaram enrugados e atrofiados no seu desenvolvimento).

A aplicação de fluazifop-p-butil + fomesafen foi realizada aos 15 dias após a semeadura da soja, utilizando um pulverizador costal com bicos do tipo leque XR 110.03, à pressão de $45 \mathrm{lb} \mathrm{pol}^{-2}$, calibrado para aplicação de $300 \mathrm{~L} \mathrm{ha}^{-1}$ de calda.

A identificação e a determinação da densidade e massa seca das plantas daninhas foram realizadas aos 46 dias após a aplicação do herbicida.

Realizou-se a análise de variância conjunta (teste F) dos experimentos (Tabela 2), sendo as interações desmembradas e as médias comparadas pelo teste de Duncan.

Tabela 2 - Médias da massa seca de plantas daninhas (MSPD) avaliada aos 46 dias após a aplicação de glyphosate, do número de vagens por planta e de grãos por vagem e da produtividade (PROD) $\left(\mathrm{kg} \mathrm{ha}^{-1}\right)$ da soja em função do manejo da cobertura de milheto

\begin{tabular}{|l|c|c|c|c|}
\hline $\begin{array}{c}\text { Manejo do } \\
\text { milheto }\end{array}$ & $\begin{array}{c}\text { MSPD } \\
\left(\mathrm{g} \mathrm{m}^{-2}\right)\end{array}$ & $\begin{array}{c}\text { Vagens } \\
\text { por planta }\end{array}$ & $\begin{array}{c}\text { Grãos por } \\
\text { vagem }\end{array}$ & $\begin{array}{c}\text { PROD } \\
\left(\mathrm{kg} \mathrm{ha}^{-1}\right)\end{array}$ \\
\hline Glyphosate & $86,32 \mathrm{a}$ & $21,20 \mathrm{a}$ & $2,72 \mathrm{a}$ & $2.868,8 \mathrm{a}$ \\
\hline Rolo-faca & $125,01 \mathrm{~b}$ & $10,92 \mathrm{~b}$ & $2,05 \mathrm{~b}$ & $1.030,0 \mathrm{~b}$ \\
\hline
\end{tabular}

Médias seguidas pela mesma letra minúscula na coluna não diferem entre si pelo teste de $\mathrm{F}$ a $5 \%$ de probabilidade.

\section{RESULTADOS E DISCUSSÃO}

A produção de matéria seca do milheto, nas condições experimentais, foi de $13,8 \mathrm{tha}^{-1}$, quantificada por ocasião do seu manejo, sendo ela bem próxima da obtida por Oliveira et al. (2002), de $14,18 \mathrm{tha}^{-1}$, produzida em monocultivo.

No plantio do milheto, foram identificadas as espécies daninhas Acanthospermum hispidum, Ageratum conyzoidis, Commelina benghalensis, Cyperus rotundus, Digitaria bicornis, Emilia sonchifolia, Mormodica charantia, Panicum maximum, Portulaca oleracea e Senna obtusifolia.

Após a formação da palhada (46 dias após a aplicação de glyphosate), a quantidade de 
massa seca total acumulada pelas espécies daninhas foi menor no tratamento em que o milheto foi manejado com aplicação deste herbicida, em relação ao manejo com rolo-faca (Tabela 2), refletindo em menor efeito da competição das espécies daninhas, o que possibilitou melhor desempenho produtivo dos cultivares de soja, resultando em maior quantidade de vagens por planta $(48,5 \%)$ e de grãos por vagem $(24,6 \%)$ (Tabela 2$)$. Um dos fatores responsáveis pelo maior acúmulo de massa seca total das plantas daninhas e, conseqüentemente, maior grau de interferência com a cultura (Horta et al., 2004) foi a maior desuniformidade de cobertura nas áreas manejadas com rolo-faca, expondo o solo à radiação solar, o que, segundo Furness \& Upadhyaya (2002), pode favorecer o aumento na população das espécies daninhas. Por outro lado, a palhada formada após a aplicação de glyphosate foi uniformemente distribuída sobre o solo, reduzindo os efeitos de exposição deste.
Os cultivares apresentaram comportamento distinto apenas em relação ao peso de 100 grãos (Tabela 3), sendo esse valor maior para o cultivar Conquista. A baixa produtividade dos cultivares no manejo com glyphosate (próximo a $3.000 \mathrm{~kg} \mathrm{ha}^{-1}$ ) (Tabela 2) pode ser devido ao intervalo entre a implantação da cultura e dessecação da cobertura vegetal, que nesse caso foi de 30 dias. Segundo Fleck et al. (2002), quanto maior o atraso da semeadura da soja em relação à aplicação do dessecante, maior será a interferência das plantas daninhas na produtividade da cultura.

Na avaliação realizada aos 46 dias após a aplicação das doses do herbicida fluazifop-pbutil + fomesafen na cultura da soja, além de C. rotundus (presente sob alta densidade $71,8 \%$ - em ambos os tratamentos para formação da cobertura vegetal) e E. sonchifolia (com maior incidência no tratamento em que o milheto recebeu a aplicação de glyphosate - 3,8\%),

Tabela 3 - Resumo da análise de variância conjunta dos efeitos dos tratamentos sobre as variáveis número de vagens por planta e de grãos por vagem, produtividade (PROD), peso de 100 grãos (PCG), massa seca de plantas daninhas (MSPD), densidade total de plantas daninhas (TPD), do total de monocotiledôneas (TPDM) e do total de plantas daninhas dicotiledôneas (TPDD)

\begin{tabular}{|c|c|c|c|c|c|c|c|c|c|}
\hline \multirow{3}{*}{ Fontes de variação } & \multirow{3}{*}{ GL } & \multicolumn{8}{|c|}{ Quadrados médios } \\
\hline & & \multicolumn{8}{|c|}{ Variáveis } \\
\hline & & $\begin{array}{l}\text { Vagens por } \\
\text { planta }\end{array}$ & $\begin{array}{l}\text { Grãos por } \\
\text { vagem }\end{array}$ & PROD & PCG & MSPD & TPD & TPDM & TPDD \\
\hline BLOCO & 3 & $201,5665^{*}$ & $0,876960 * *$ & $770.367,7 * *$ & 13,80075 & $2.124,29$ & $9.829,815$ & $10.810,63$ & 331,9728 \\
\hline $\begin{array}{l}\text { Manejo do milheto } \\
(\mathrm{Mm})\end{array}$ & 1 & $882,7963 * *$ & $0,882919^{*}$ & $2.535 .521,0 * *$ & 11,69964 & $17.964,54 * *$ & $10.325,33$ & 7767,34 & 181,7408 \\
\hline $\begin{array}{l}\text { Cultivares de soja } \\
\text { (Cs) }\end{array}$ & 1 & 0,627919 & 0,135469 & $70.227,0$ & $233,5072 * *$ & 0,0120 & $12.033,33$ & $16.331,94$ & 327,6075 \\
\hline $\begin{array}{l}\text { Manejo de plantas } \\
\text { daninhas (Mpd) }\end{array}$ & 2 & $436,9816^{* *}$ & $1,571033 * *$ & $1.806 .785,0^{* *}$ & 4,297004 & $12.3231,3^{* *}$ & $55.770,34^{*}$ & $32.910,25$ & $2.997,601 * *$ \\
\hline $\mathrm{Mm} \times \mathrm{Cs}$ & 1 & 88,86242 & 0,027552 & $13.736,33$ & 1,910778 & 7,648033 & $33.542,84$ & $29.726,63$ & 115,196 \\
\hline Mm x Mpd & 2 & 223,9704 & 0,054900 & $546.774,3^{*}$ & 1,043447 & $4.714,10$ & $61.416,57 *$ & $64.544,06^{*}$ & 197,001 \\
\hline Cs X Mpd & 2 & 14,47123 & 0,144750 & $52.671,0$ & 0,141169 & 378,5358 & $19.443,25$ & $19.025,05$ & 9,9877 \\
\hline Mm x Cs x Mpd & 2 & 61,57223 & 0,074258 & $51.770,33$ & 0,221231 & 915,4862 & $63.609,9^{*}$ & $49.374,27 *$ & $916,0^{*}$ \\
\hline RESÍDUO & 33 & 72,43733 & 0,141465 & $139.771,1$ & 5,921337 & $1.906,206$ & $12.475,13$ & $11.406,80$ & 201,8444 \\
\hline $\mathrm{CV}(\%)$ & & 63,6 & 38,9 & 76,7 & 13,6 & 41,3 & 86,4 & 98,4 & 68,4 \\
\hline
\end{tabular}

$*$ e** - significativo a 5 e $1 \%$, respectivamente, pelo teste $\mathrm{F}$. 
houve significativa infestação de $D$. bicornis $(7,4 \%)$, Brachiaria plantaginea $(2,2 \%)$, Richardia brasilienses (3,4\%) e Blainvillea latifolia $(1,8 \%)$ na área manejada com rolo-faca, com predomínio de monocotiledôneas, em razão da alta densidade de C. rotundus. Esta espécie prevaleceu desde o cultivo do milheto, possivelmente em decorrência do revolvimento do solo, no preparo convencional, o qual favorece a propagação e o estabelecimento desta espécie (Jakelaitis et al., 2003).

Trezzi \& Vidal (2004) verificaram que a utilização de 4,0 t ha-1 de palha de milheto resultou em supressão de $91 \%$ da população de $B$. plantaginea; no entanto, no presente ensaio, mesmo sob 13,8 $\mathrm{t} \mathrm{ha}^{-1}$ de palha (associada à aplicação de fluazifop-p-butil + fomesafen) ainda se obteve incidência de 2,2\% dessa espécie na área, visto que nem a cobertura vegetal nem o herbicida proporcionaram o controle total da espécie. Pereira et al. (2000) constataram que a aplicação de fluazifop-pbutil + fomesafen $\left(250+250 \mathrm{~g} \mathrm{ha}^{-1}\right)$ resultou em controle insatisfatório de $B$. plantaginea aos 35 dias após a emergência da soja cultivada sobre palha de aveia-preta (Avena strigosa).

Todavia, o manejo químico das plantas daninhas com aplicação de fluazifop-p-butil + fomesafen, em pós-emergência na cultura da soja, proporcionou redução no número total das espécies presentes (Tabela 4), semelhante aos resultados encontrados por Timossi \& Durigan (2002), aos 30 dias após a aplicação deste herbicida na dose de 200+250 $\mathrm{g} \mathrm{ha}^{-1}$. A redução na população de plantas daninhas resultou em maior quantidade de vagens por planta e de grãos por vagem, refletindo em maior produtividade, em relação ao tratamento em que as plantas daninhas não foram controladas. Não houve diferença significativa para essas variáveis entre as doses utilizadas, exceto com relação à produtividade, em que a utilização de $200+250 \mathrm{~g} \mathrm{ha}^{-1}$ de fluazifop-p-butil + fomesafen proporcionou aumento desse valor, provavelmente em função do maior peso dos grãos sob este tratamento, dada a menor quantidade de grãos chochos por hectare (Tabela 4).

A formação da palha de milheto mediante a aplicação de glyphosate proporcionou significativa redução na população de plantas daninhas na cultura da soja, em relação ao manejo com rolo-faca, mesmo quando estas não receberam posteriormente a aplicação de fluazifop-p-butil + fomesafen (Tabela 5). Independentemente da dose do herbicida, a produtividade da soja foi maior quando foi utilizado o glyphosate em vez do rolo-faca (Tabela 5).

Como a maioria dos trabalhos indica de 15 a 40 dias após a emergência da soja como o intervalo crítico de controle das plantas daninhas (Carvalho \& Velini, 2001; Melo et al., 2001; Meschede et al., 2002, 2004), é preciso que o método de controle escolhido propicie baixa população destas dentro desse período, com o intuito de não interferir na produtividade da cultura. Para isso, a utilização de glyphosate como dessecante para formação da palha de milheto foi de suma importância no manejo das plantas daninhas na cultura sucessora, uma vez que este, por ser um herbicida nãoseletivo, além de dessecar a cultura do milheto, promoveu o controle das espécies daninhas emergidas por ocasião da aplicação, resultando em menor população destas na fase inicial de crescimento da soja.

Tabela 4 - Médias da massa seca de plantas daninhas (MSPD) ( $\mathrm{g} \mathrm{m}^{-2}$ ), total de plantas daninhas (TPD), total de plantas daninhas dicotiledôneas (TPDD), número de vagens por planta de soja, número de grãos por vagem, de produtividade de grãos (PROD) e de produção de grãos chochos (GC) $\left(\mathrm{kg} \mathrm{ha}^{-1}\right)$ da soja, em função da aplicação de fluazifop-p-butil + fomesafen nesta cultura

\begin{tabular}{|c|c|c|c|c|c|c|c|}
\hline $\begin{array}{c}\text { Doses de fluazifop-p- } \\
\text { butil + fomesafen } \\
\left(\mathrm{g} \mathrm{ha}^{-1}\right)\end{array}$ & MSPD & TPD & TPDD & $\begin{array}{c}\text { Vagens por } \\
\text { planta }\end{array}$ & $\begin{array}{c}\text { Grãos por } \\
\text { vagem }\end{array}$ & PROD & GC \\
\hline 0 & $206 \mathrm{a}$ & $197,15 \mathrm{a}$ & $36,49 \mathrm{a}$ & $8,86 \mathrm{~b}$ & $1,51 \mathrm{~b}$ & $574 \mathrm{c}$ & $155,2 \mathrm{~b}$ \\
\hline $100+125$ & $67,83 \mathrm{~b}$ & $100,73 \mathrm{~b}$ & $14,32 \mathrm{~b}$ & $23,30 \mathrm{a}$ & $2,68 \mathrm{a}$ & $2.014 \mathrm{~b}$ & $212,4 \mathrm{a}$ \\
\hline $200+250$ & $43,17 \mathrm{~b}$ & $89,91 \mathrm{~b}$ & $11,49 \mathrm{~b}$ & $20,10 \mathrm{a}$ & $2,75 \mathrm{a}$ & $3.260 \mathrm{a}$ & $156,0 \mathrm{~b}$ \\
\hline
\end{tabular}

Médias seguidas pela mesma letra não diferem entre si pelo teste de Duncan a 5\% de probabilidade. 
Tabela 5 - Médias do número total de plantas daninhas (TPD), do total de monocotiledôneas (TPDM) e de produtividade da soja (PROD) $\left(\mathrm{kg} \mathrm{ha}^{-1}\right)$, em função da interação manejo do milheto x manejo de plantas daninhas com fluazifop-p-butil + fomesafen

\begin{tabular}{|c|c|c|c|c|c|c|c|c|c|}
\hline \multirow{3}{*}{$\begin{array}{l}\text { Manejo do } \\
\text { milheto }\end{array}$} & \multicolumn{9}{|c|}{ Doses de fluazifop-p-butil + fomesafen $\left(\mathrm{g} \mathrm{ha}^{-1}\right)$} \\
\hline & \multicolumn{3}{|c|}{0} & \multicolumn{3}{|c|}{$100+125$} & \multicolumn{3}{|c|}{$200+250$} \\
\hline & TPD & TPDM & PROD & TPD & TPDM & PROD & TPD & TPDM & PROD \\
\hline $\begin{array}{c}\text { Herbicida } \\
\text { (glyphosate) }\end{array}$ & $116,0 \mathrm{Ab}$ & $78,5 \mathrm{Ab}$ & $791,2 \mathrm{Ba}$ & $96,5 \mathrm{Aa}$ & 88 Аа & $2.864,0 \mathrm{Aa}$ & $48,5 \mathrm{Ab}$ & $35,0 \mathrm{Ab}$ & $3.180,0 \mathrm{Aa}$ \\
\hline Rolo-faca & $278,3 \mathrm{Aa}$ & $242,8 \mathrm{Aa}$ & $357,2 \mathrm{Bb}$ & $105,0 \mathrm{Ba}$ & $84,83 \mathrm{Ba}$ & $1.164,0 \mathrm{Ab}$ & $131,3 \mathrm{Ba}$ & $120,8 \mathrm{Ba}$ & $1.569,2 \mathrm{Ab}$ \\
\hline
\end{tabular}

Médias seguidas pela mesma letra minúscula na coluna não diferem entre si pelo teste de $\mathrm{F}$ a $1 \%$ de probabilidade, e por maiúscula na linha, para cada característica (TPD, TPDM e PROD), não diferem entre si pelo teste de Duncan a 5\% de probabilidade.

Contudo, quando a palha foi formada com auxílio do rolo-faca, ocorreu intensa reinfestação da área de cultivo, em função da desuniformidade de distribuição da palha sobre o solo e do corte de estruturas vegetativas de algumas espécies, induzindo a proliferação destas, como no caso de $C$. rotundus, sendo esta a espécie daninha mais representativa na área experimental. A menor produtividade dos cultivares Conquista e Celeste foi verificada sob a maior infestação de plantas daninhas, obtida na ausência de controle destas, corroborando os resultados obtidos por Pires et al. (2005) ao avaliarem o rendimento de grãos dos cultivares Emgopa 315, Conquista, Coodete 211 e Vencedora.

A utilização de ambas as doses de fluazifopp-butil + fomesafen proporcionou semelhante controle das plantas daninhas, além de ter resultado em produtividades equivalentes (Tabela 5). Assim, verifica-se que a dose de fluazifop-p-butil + fomesafen pode ser reduzida em 50\%, o que está em conformidade corrobora com Lima \& Machado Neto (2001). Entretanto, para que ocorra redução da dose do herbicida aplicado em pós-emergência no cultivo da soja, há necessidade de que a palha do milheto seja manejada com a aplicação de glyphosate, possibilitando manter o controle de plantas daninhas em níveis satisfatórios.

\section{LITERATURA CITADA}

BARROS, A. C. et al. Eficiência e seletividade do lactofen em mistura com outros latifolicidas, no controle de plantas daninhas na cultura da soja. R. Bras. Herbic., v. 1, n. 1, p. 79-84, 2000.
BIANCHI, M. A. Manejo integrado de plantas daninhas no sistema plantio direto. In: SEMINÁRIO NACIONAL SOBRE MANEJO E CONTROLE DE PLANTAS DANINHAS EM PLANTIO DIRETO, 2., 1999, Passo Fundo. Resumos... Passo Fundo: Aldeia Norte, 1999. p. 53-63.

CARVALHO, F. T.; VELINI, E. D. Períodos de interferência de plantas daninhas na cultura da soja. I - Cultivar IAC-11. Planta Daninha, v. 19, n. 3, p. 317-322, 2001.

CHEMALE, V. M.; FLECK, N. G. Avaliação de cultivares de soja (Glycine max (L.) Merrill) em competição com Euphorbia heterophylla L. sob três densidades e dois períodos de ocorrência. Planta Daninha, v. 5, n. 2, p. 36-45, 1982.

CHIAPPA, A. C. Crédito agrícola - produção e exportação de soja. Disponível em: <http://www.agronline.com.br/ artigos/artigo.php?id=1>. Acesso em: 5 set. 2005.

CORREIA, N. M. et al. Palha de sorgo associada ao herbicida imazamox no controle de plantas daninhas na cultura da soja em sucessão. Planta Daninha, v. 23, n. 3, p. 483-489, 2005.

EMPRESA BRASILEIRA DE PESQUISA AGROPECUÁRIA - EMBRAPA. Centro Nacional de Pesquisa de Solos. Sistema brasileiro de classificação de solos. Brasília: 1999. 412 p.

ERASMO, E. A. L. et al. Potencial de espécies utilizadas como adubo verde no manejo integrado de plantas daninhas. Planta Daninha, v. 22, n. 3, p. 337-342, 2004.

FACELLI, J. M.; PICKETT, S. T. A. Plant litter: light interception and effects of an old-field plant community. Ecology, v. 72, n. 3, p. 1024-1031, 1991.

FLECK, N. G.; CANDEMIL, C. R. G. Interferência de plantas daninhas na cultura da soja. Ci. Rural, v. 25, n. 1, p. 27-32, 1995. 
FLECK, N. G. et al. Período crítico para controle de Brachiaria plantaginea em função de épocas de semeadura da soja após dessecação da cobertura vegetal. Planta Daninha, v. 20, n. 1, p. 53-62, 2002.

FURNESS, N. H.; UPADHYAYA, M. K. Differential susceptibility of agricultural weeds to ultraviolet-B radiation. Can. J. Plant Sci., v. 82, n. 4, p. 789-796, 2002.

HORTA, A. C. S. et al. Interferência de plantas daninhas na beterraba transplantada e semeada diretamente. Acta Sci., v. 26, n. 1, p. 47-53, 2004.

JAKELAITIS, A. et al. Efeitos de sistemas de manejo sobre a população de tiririca. Planta Daninha, v. 21, n. 1, p. 89-95, 2003.

LIMA, E. A. Espécies para a cobertura de solo e seus efeitos sobre a vegetação espontânea e rendimento da soja em plantio direto, em Campos dos Goytacazes, RJ. 2002. 62 f. Dissertação (Mestrado em Produção Vegetal) Universidade Estadual do Norte Fluminense, Campos dos Goytacazes, 2002.

LIMA, P. R. F.; MACHADO NETO, J. G. Otimização da aplicação de fluazifop-p-butil em pós-emergência na cultura da soja (Glycine max). Planta Daninha, v. 19, n. 1, p. 85-95, 2001.

MELO, H. B. et al. Interferência das plantas daninhas na cultura da soja cultivada em dois espaçamentos entre linhas. Planta Daninha, v. 19, n. 2, p. 187-191, 2001.

MESCHEDE, D. K. et al. Período crítico de interferência de Euphorbia heterophylla na cultura da soja sob baixa densidade de semeadura. Planta Daninha, v. 20, n. 3, p. 381-387, 2002.

MESCHEDE, D. K. et al. Período anterior à interferência de plantas daninhas em soja: estudo de caso com baixo estande e testemunhas duplas. Planta Daninha, v. 22, n. 2, p. 239-246, 2004.

NIMBAL, C. I. et al. Phytotoxicity and distribution of sorgoleone in grain sorghum germplasm. J. Agric. Food Chem., v. 44, n. 5, p. 1343-1347, 1996.

OLIVEIRA, T. K. et al. Plantas de cobertura e seus efeitos sobre o feijoeiro em plantio direto. Pesq. Agropec. Bras., v. 37, n. 8, p. 1079-1087, 2002.
PEREIRA, E. S. et al. Avaliações qualitativas e quantitativas de plantas daninhas na cultura da soja submetida aos sistemas de plantio direto e convencional. Planta Daninha, v. 18, n. 2, p. 207-216, 2000.

PIRES, J. L. F. et al. Redução na dose do herbicida aplicado em pós-emergência associada a espaçamento reduzido da cultura da soja para controle de Brachiaria plantaginea. Planta Daninha, v. 19, n. 3, p. 337-343, 2001.

PIRES, F. R. et al. Potencial competitivo de cultivares de soja em relação às plantas daninhas. Planta Daninha, v. 23, n. 4, p. 575-581, 2005.

RODRIGUES, B. N.; ALMEIDA, F. S. Guia de herbicidas. 5.ed. Londrina: Edição dos autores, 2005. 592 p.

SOUZA, P. I. M. et al. BRS Celeste - nova cultivar de soja para o sistema de produção de grãos no cerrado. Pesq. Agropec. Bras., v. 35, n. 2, p. 467-470, 2000.

SOUZA, P. I. M. et al. Cultivar de soja BRS Celeste. Brasília: Embrapa Cerrado, 2001. 2 p. (Recomendação Técnica, 34)

SPADOTTO, C. A. et al. Avaliação de parâmetros para o monitoramento da interferência de plantas daninhas na cultura de soja (Glycine max L.). Planta Daninha, v. 10, n. 1/2, p. 33-38, 1992.

TEASDALE, J. R.; MOHLER, C. L. Light transmittance, soil temperature, and soil moisture under residue of hairy vetch and rye. Agron. J., v. 85, n. 3, p. 673-680, 1993.

TIMOSSI, P. C.; DURIGAN, J. C. Doses reduzidas de fluazifop-p-butil + fomesafen no controle de plantas daninhas na cultura da soja. Planta Daninha, v. 20, n. 3, p. 439-447, 2002.

TREZZI, M. M.; VIDAL, R. A. Potencial de utilização de cobertura vegetal de sorgo e milheto na supressão de plantas daninhas em condição de campo: II - Efeitos da cobertura morta. Planta Daninha, v. 22, n. 1, p. 1-10, 2004.

VIDAL, R. A.; THEISEN, G. Efeito da cobertura do solo sobre a mortalidade de sementes de capim-marmelada em duas profundidades no solo. Planta Daninha, v. 17, n. 3, p. 339-344, 1999. 